\title{
DIE GESAGSKRISIS
}

\section{Aardstorting}

Wat vandag op die terrein van die teologie en met name in die Etiek gebeur, kan ons miskien die beste aandui met die woord „aardstorting". Waar dit gaan oor verhoudinge tussen mense in en buite die huwelik, politieke, maatskaplike en sosiale probleme, kortom, orals waar gesag ter sprake kom, sien ons 'n geweldige grondverskuiwing. Met ander woorde ons belewe 'n ontsettende krisis van die gesag.

Hierdie gesagskrisis werk deur op alle terreine van die lewe, sowel in die kerk as in die samelewing. Wat die gesag en die verskillende gesagsstrukture in die samelewing aanbetref, belewe ons 'n aardstorting. Gevolglik tree die teologie van die rewolusie, die ondermyning van die Skrifgesag, die ontbinding van die huwelik en die hoë egskeidingssyfer, die steun van kerke en vorste aan terroristiese organisasies en die opstand aan universiteite na vore. Daar hoef nouliks meer genoem te word om die aktualiteit van die onderwerp nog verder te verduidelik.

\section{Wat is gesag?}

Om die krisis in allerlei gesagsstrukture te kan aandui, moet ons eers goed weet wat gesag is. Gesag is nie dieselfde as mag nie. „Mag" is die vermoë om te kan handel, om oor iets of iemand te kan heers. Wanneer iemand deur 'n hoër norm of instansie gemagtig word om mag uit te oefen, noem ons dit ,gesag”. Gesag is dus die bevoegdheid om mag uit te oefen.

Gesag kan alleen daar wees waar ongelykheid is. Gesag druk daarom 'n verhouding uit tussen 'n meerdere en 'n mindere. Daarom vra gesag altyd gehoorsaamheid.

In huisgesin, kerk, maatskappy en staat vind ons 'n gesagstruktuur. Ouers oefen gesag uit oor hul kinders, onderwysers oor hul leerlinge, die owerheid oor sy onderdane.

$\mathrm{H}$. Bavinck maak onderskeid tussen twee vorme van gesag nl., juridiese en etiese gesag. ${ }^{1}$ Met die eerste vorm van gesag bedoel hy gesag wat rus op 'n regsgrond. Regtens is aan ouers, onderwysers, owerheidspersone gesag gegee. Etiese gesag rus egter op voortreflike eienskappe soos op 'n man se groot wetenskaplike bekwaamheid of sy kunstenaar-wees. Deur hulle kundigheid dwing hulle gesag af.

Max Weber onderskei selfs drie soorte van gesag, nl. charismatiese, tradisionele en legale gesag. ${ }^{2}$ Charismatiese en tradisionele gesag kom enigsins ooreen met wat $\mathrm{H}$. Bavinck etiese gesag noem.

Ons glo dat beide soorte van gesag, sowel die juridiese as die etiese gesag, gewortel is in God. Alle gesag kan tot God herlei word. Daarom skryf die apostel Paulus in Rom. $13: 1$ : „Daar is geen gesag behalwe van God nie". Die Griekse woord eksousia beteken letterlik mag of bevoegdheid. In die N.T. word hierdie woord in 
verskillende betekenisse gebruik. In sy briewe dui Paulus met hierdie woord ook die onsigbare magte van engele en demone aan (vgl. Ef. 1, 21; 6, 12; Kol. 2, 15). In Rom. 13 kry die woord eksousia die betekenis van owerheid. Wanneer Paulus skrywe: „Alle eksousiai kom van God", wil hy daarop wys dat daar in elke gesagsstruktuur (of dit nou die owerheid, ouer of die kerklike amp is) 'n vertikale lyn is.

Ons glo dat God absolute gesag besit. Hy is die Skepper. In die ou gereformeerde dogmatieke word gepraat van die divina auctoritas, die goddelike gesag. Gods gesag rus in sy wese. God is daarom ook die gesagsuitdeler bv. aan ouers, ampsdraers, owerhede ens. Gesag is nie iets wat gegryp kan word nie. Gesag word ontvang. En dit is God wat gesag gee. By die begin van die skepping het God sy gesag aan Adam gegee. Adam het gesag ontvang. Hy is deur God aangestel om te regeer. (Gen. $1: 28$ ). Na die paradysrewolusie het Adam sy gesag verloor. Deur God se genade is dit weer enigermate herstel. Maar God het tog in die eerste plek sy gesag gegee aan Jesus Christus, die laaste Adam. Christus het as die gekruisigde en opgestane Here (Kurios) alle eksousia ontvang in hemel en op aarde (Matt. 28 : 18). Eksouia beteken hier bevoegdheid. Dit is legale, juridiese gesag, soos $\mathrm{H}$. N. Ridderbos in sy verklaring van Mattheüs skryf. ${ }^{3}$ Die gesagsoordrag van die Vader aan Christus (N.B. die werkwoord gegee in Matt. $28: 18$ ) het plaas gevind in verband met die kruis en die opstanding van Christus. Ons vind dieselfde gedagte by Paulus in Fil. $2: 8,9$.

In die briewe aan die Efesiërs en die Kolossense waarin Paulus die kosmiese betekenis van die werk van Christus beskrywe, druk die apostel die gesag van Christus uit met die woord: kefalè, ,hoof”. Christus is die Hoof van Kerk en kosmos (vgl. Ef. 1, 22; Kol. 1 : 18). Alle gesag kom dus van Christus. Christus oefen wel sy gesag in die Kerk op 'n ander wyse uit as in die wêreld. In die Kerk word die Hoofskap van Christus erken en bely. ${ }^{4}$ In die wêreld word die heerskappy van Christus nie erken en bely nie. Tog regeer Christus ook daar, al is dit op 'n verborge manier. Paulus skryf in Ef. $1: 22,23$ dat Christus die Hoof van die Kerk is en dan noem hy die Kerk die pleroma van Christus. Ek sluit my hier aan by die nuwere eksegese van die begrip volheid (pleroma) en verstaan dit dan as gebied of dominium. ${ }^{5}$ Ons kan dan Ef. 1 : 23 soos volg parafraseer: die Kerk is die domein van Christus wat oor alles domineer ${ }^{6}$ en dan beteken dit dat die heerskappy van Christus oor die gehele kosmos nog verborge is maar dat dit reeds in die Kerk erken en bely en geeerbiedig word.

In die Kerk oefen Christus sy gesag uit deur middel van die ampte. In die wêreld doen Christus dit deur die gesagsstrukture wat God in die skepping neergelê het. Daarom kan die apostel skrywe: alle eksousiai is van God en deur God ingestel.

\section{Gesag in die Kerk}

Ons gaan eers kyk hoe die gesag in die Kerk uitgeoefen word 
en wat die doel van die gesag in die Kerk is en vervolgens kyk hoe Christus sy gesag in die wêreld uitoefen en met watter doel sy gesag in die wêreld uitgeoefen word.

Alle gesag in die Kerk is gesag van Christus. Christus het sy gesag uitgeoefen toe Hy sy Kerk vergader het. Selfs die Fariseërs het iets van sy gesag aangevoel. Hulle was verslae oor sy leer, want sy Woord was met gesag (eksousia) volgens Luk. 4, 32. Jesus het gesag om sondes te vergewe en ook om siekes te genees. $\mathrm{Na}$ sy opstanding het Christus sy gesag wat Hy deur sy lyding en sterwe verwerf het, openlik geproklameer (Matt. $28: 18$ ).

Wanneer ons vervolgens ag gee op die gesagsuitoefening van Christus in sy Kerk, sien ons dat Christus deur middel van sy Gees sy gesag in die Kerk realiseer. Die N.T. bied ons twee woorde wat in hierdie verband besonder belangrik is.

Eerstens is daar die woord eksousia wat ons met gesag of volmag kan vertaal, soos ons reeds gesien het. Hierdie begrip wys ook op die vryheid en die reg om op te tree. ${ }^{7}$

In die N.T. word eksousia altyd verbind met Christus. Gesag is aan sy persoon en werk onlosmaaklik verbonde. Christus het bevoegdheid om te handel, om te regeer. Die Vader het dit aan Hom gegee en dit is alles omvattend, in hemel en op aarde. Alle gesag is dus in feite gesag van Christus. Alle menslike gesag is dus nie outonoom nie, maar afhanklik van die gesag van Christus.

In die Kerk oefen Christus sy gesag uit deur die Heilige Gees. Dit bring ons by 'n tweede kernwoord uit die N.T. naamlik, die woord dunamis. Word eksousia altyd gebruik in verband met Christus, die dunamis staan altyd in die N.T. in verband met die Heilige Gees. Wel is daar in die N.T. ook sprake van die dunamis, die krag van Christus, maar dan is dit altyd die krag wat Christus uitoefen deur sy Gees. ${ }^{8}$

Eksousia van Christus en dunamis van die Heilige Gees is nou op mekaar betrokke. Deur die mag van die Gees word die gesag van Christus erken. Daar is in die N.T. 'n wedersydse korrelasie van eksousia en dunamis, van gesag en mag, potestas en potentia, bevoegdheid en bekwaamheid, instituut en charisma, amp en kundigheid. ${ }^{9}$ Wanneer ons hierdie twee begrippe uit mekaar ruk en die onderlinge samehang verbreek, kry ons aan die een kant 'n ooraksentuering van outoriteit wat kan ontaard in diktatoriale gesag en andersyds loop ons die gevaar om te verval in 'n funksionele gesag.

Christus het in sy Kerk die gesag verbind aan die ampte en hulle het die salwing met die Gees. Die ampsdraers in die Kerk het dus die eksousia van Christus. Tewens mag hulle reken op die dunamis van die Heilige Gees. Christus wat roep tot gesag gee ook die krag, die wysheid, die bestuursbekwaamheid om die gesag te kan uitoefen in sy naam.

\section{Gesag in die wêreld}

In die wêreld oefen Christus kragtens die eksousia wat Hy van sy Vader ontvang het ook gesag uit. Die aard van sy gesagsoefening 
in die wêreld is egter anders as in die Kerk. In die Kerk werk sy gesag en die krag wat daarby verleen word tot verlossing. Dit beoog die verlossing van die sonde en die heiliging van die lewe. ${ }^{10}$ In die wêreld verleen Christus ook eksousia. Daar is geen gesag behalwe van God nie.

Wat is die bedoeling van God met die verskillende gesagsstrukture in die wêreld? God wat die Skepper is, is ook die Verlosser. In verband met sy verlossingswerk wil God die orde in die wêreld handhaaf." In 1 Tim. 2 : 1, 2 wys Paulus op die voorbede vir konings en almal wat hooggeplaas is in verband met die verlossingsplan van God. Ek dink hier aan die beroemde uitdrukking van B. Holwerda: „God is Zaligmaker; daarom wil Hij het overheidszwaard gehanteerd zien ter beveiliging der orde; daarom wil Hy dat de overheid met het zwaard de preekstoel veilig stelt".12

Almal wat geroep is om gesag te oefen, wat dus eksousia ontvang het, mag ook reken op en ook staat maak op die dunamis. God gee die gawe van wysheid, insig, bestuursbekwaamheid; Hy verleen ook magsmiddele om die gesag te kan uitoefen.

\section{Die bron van alle gesagskrisis}

Gesagskrisis sowel in Kerk as maatskappy ontstaan daar waar nie meer erken word dat alle gesag deur God ingestel is nie. Waar die band tussen God of Christus en die gesag deurgesny word, kom onherroepelik 'n gesagskrisis.

J. J. Rousseau, die vader van die Franse Rewolusie, het in sy bekende werk Contrat Social geskryf dat gesag nie vertikaal gestruktureer is nie. Daar bestaan nie so iets as gesag bo die mens nie. Tog het selfs Rousseau behoefte gehad om die gesag wat nodig is om die samelewing in stand te hou êrens te fundeer. Rousseau bou daarom die gesag op 'n verdrag van individue. ${ }^{13}$ Volgens Groen van Prinsterer is dit egter die begin van die rewolusie. Hierdie beskouing moet volgens Groen van Prinsterer 'n staatsvernietigende uitwerking hê. Die skrikbewind in die Franse Rewolusie was dan ook nie 'n uitwas van Rousseau se beskouinge nie, maar 'n eerste konsekwensie van Rousseau se staatsleer.

Selfs die mens wat hom van God losgemaak het, besef dat daar op die een of ander manier gesag nodig is. Anders verval die wêreld in chaos en anargie. Daarom sê die leier van die Chinese Kommunistiese Party, Mao Tse-toeng: „Mag kom uit die loop van 'n geweer". Hy wat die dunamis kan verower, het ook die eksousia.

Alle gesagskrisisse word veroorsaak wanneer die oorsprong van gesag verskuif word van God na die mens. Daar word nog wel erken dat gesag iets is wat gegee moet word, maar dit is nie God wat gesag gee nie. Dit kom uit die hand van mense. 'n Duidelike voorbeeld van hierdie nuwere siening op die gesag kan ons vind by dr. H. J. van Zuthem, hoogleraar in Sosiologie aan die V.U. te Amsterdam. In sy boek Gezag en zeggenschap skrywe van Zuthem soos volg oor die verskil tussen gesag en mag: „Maar het grote verschil met macht is, dat bij gezag op een of andere manier sprake 
is van instemming van degenen, die aan die macht zich onderwerpen. Deze machtsonderworpenen schikken zich niet tegenstribbelend, maar instemmend. Zij rechtvaardigen als het ware het bestaan van macht door de juistheid er van te beklemtonen. We noemen dat in de sociologie het legitimeren van macht. Gezag is daarom gelegitimeerde macht". ${ }^{14}$

Hier kry ons ' $n$ absolute wysiging van die gesagsbegrip. Volgens die Skrif is gesag wat die kerk betref ministriële magisa en wat die owerheid betref gedelegeerde mag. „Nee”, sê Van Zuthem, „gesag is gelegitimeerde mag". Die Bybel stel: gesag word deur God gegee. Van Zuthem ontken dit en verklaar: „Gesag word van mense ontvang". Van Zuthem ontken dat gesag van God kom, hoogstens die middele tot gesagsuitoefening. ${ }^{15}$,De diepste bron van het gezag is niet, dat het van God komt". ${ }^{16} \mathrm{Hy}$ vind dan ook dat in die formulering van die Heidelbergse Kategismus in Sondag 39 (aangesien dit God behaag om ons deur hulle hand te regeer) „een gevaarlijke oproep tot aanvaarding van bestaande machtsverhoudingen kan liggen". ${ }^{17}$ Van Zuthem verwyt die protestants-christelike denkers dat hulle by die nadenke oor die gesag te min aandag bestee het aan die so belangrike proses van legitimering. ${ }^{18}$

Diepste bron en laaste motief van die gesag is volgens Van Zuthem die humaniteit, die menslikheid van die verhoudinge. ${ }^{9}$ Wat doel van die gesag is, het by Van Zuthem die bron geword. Gesag dien tot bevordering van geregtigheid en solidariteit tussen mense. Van Zuthem beroep hom vir sy gesagsbeskouing op die Bybel en wel op die woorde van Paulus in Rom. 13:4 jou ten goede. Maar hy verwaarloos die eerste gedeelte van dieselfde teks naamlik, die owerheid is ' $n$ dienaar van God. Van Zuthem vind dit goedkoop om te sê: gesag kom van God. „Watter ellende van onmondigheid het hierdie uitspraak al nie gebring nie!" so klink sy versugting. ${ }^{20}$

In wese is hier geen verskil met Rousseau nie. Prof. S. U. Zuidema het in 'n ander verband reeds daar op gewys hoe daar in die beskouinge van Van Zuthem 'n groot mate van ooreenkoms is met die opvattinge van Herbert Marcuse, 'n neo-marxis met sy rewolusionêre maatskappykritiek. ${ }^{21}$

Wanneer God as die enigste bron van alle gesag ontken word dan ontstaan daar die behoefte om die gesag aan iets anders vas te maak, want anders verval die samelewing in anargie. Bron van gesag word dan die maatskappy, die voortreflike leier, die souwereine vors of die loop van 'n geweer. Groen van Prinsterer het egter tereg daarop gewys dat ontkenning van God as bron van gesag moet lei òf tot rewolusie of tot diktatuur. ${ }^{22}$

\section{Gevolge van die gesagskrisis in die kerk}

Ons sien sowel in die kerk as in die samelewing die katastrofale gevolge van hierdie gesagskrisis. In die kerk trek die gesagskrisis saam in 'n krisis rondom die gesag van die Bybel.

Met betrekking tot die gesag van die Heilige Skrif verkeer ons vandag in 'n tweevoudige krisis. Die eerste raak die aard van 
die Skrifgesag en die tweede die omvang van die gesag van die Bybel.

Wat die aard van die Skrifgesag aanbetref, word die Skrifgesag as geinterpreteerde gesag beskou. Die Bybel moet geïnterpreteer word met behulp van die selfverstaan van die moderne mens. Wat deur die filter van die selfverstaan gegaan het, kan as gesaghebbend beskou word. Die moderne mens bepaal dus self met behulp van ' $n$ bepaalde Skrifinterpretasie, wat in die Bybel gesaghebbend is. Die feite in die Bybel word eers geînterpreteer en wat die moderne mens daarvan verstaan, word as gesaghebbend beskou. 23

Wat vervolgens die omvang van die Heilige Skrif aanbetref, hier speel die seleksie 'n groot rol. Die nuwere teologie gaan in haar omgang met die Bybel selekterend te werk. ${ }^{24}$ Alleen die dinge uit die Bybel wat spreek oor die betekenis van Jesus Christus vir hierdie lewe is belangrik en het vir ons gesag. Jesus was nie tevrede met die bestaande orde nie. Hy het verandering gepredik. Dit doen die rewolusie ook, derhalwe was Jesus 'n rewolusionêr. Jesus het Hom beywer vir die humanum. Hy wou menslike verhoudinge herstel. Elkeen wat hom beywer vir reg en geregtigheid in die samelewing is dus Christelik besig. Die sonde moet nie soseer in die mens gesoek word nie as wel in die strukture van die samelewing. Die strukture moet opgeroep word tot bekering.

Agter hierdie opvattings sit, soos prof. W. H. Velema tereg opgemerk het, 'n oppervlakkige en verkeerde sondebeskouing en 'n matelose optimisme in die mens. ${ }^{25}$ Hier lê die wortels van die teologie van die rewolusie. Die humaniteit het die norm geword. Wat in naam van die humaniteit gedoen word is reg. Die boodskap van die Bybel is vol van "Gods pressure for change". ${ }^{26}$

Daar sit egter 'n duidelike anabaptistiese, doperse trek in heel die teologie van die rewolusie. In 'n gesprek met Van Haarsma het prof. Van Ruler daarop gewys: die geskiedenis is nou verby en nou moet die koninkryk van God gerealiseer word in 'n radikaalprogressiewe gees. ${ }^{27}$ Ons vind dit ook by Jürgen Moltmann en sy bekende boek Teologie van die hoop. Moltmann roep die kerk op tot ' $n$ eksodus uit die bestaande strukture. ${ }^{28}$ Daar is in die teologie van Moltmann 'n onmiskenbare doperse element, soos prof. W. H. Velema duidelik aangetoon het. ${ }^{29}$ Moltmann is 'n dissipel van Ernst Bloch en Ernst Bloch op sy beurt is 'n neo-marxis. In Nederland staan H. M. Kuitert weer sterk onder invloed van Moltmann.

\section{Gevolge van die gesagskrisis in die samelewing}

Ook in die samelewing ondervind ons vandag 'n geweldige krisis van die gesag. Veral sedert die Tweede Wêreldoorlog bespeur ons orals 'n verskriklike afbraak, 'n erosie van gesag en verset teen allerlei gesagsstrukture in die samelewing.

Ons kan hiervoor verskillende oorsake aanwys: In die eerste plek is daar die verwoestende uitwerking van die Eerste en in nog groter mate van die Tweede Wêreldoorlog op die gees van die mens. Elke oorlog werk demoraliserend. Dit was veral die geval by die 
twee groot wêreldoorloë in hierdie eeu. Daarby kom - en dit kan ons die tweede oorsaak van gesagskrisis noem - die penetrante invloed van die eksistensie-filosofie met sy vryheidsbegrip. Die mens is vry, vry van God en vry van alle norme. Hy eksisteer in vryheid. Hierdie wysbegeerte het ook 'n geweldige gesagsondermynende uitwerking. En dan is daar as 'n derde oorsaak vir die gesagskrisis die toename van mag wat ons by die mense van hierdie eeu kan waarneem.

Prof. H. van Riessen wys hierop in sy bekende boek Mondigheid en de machten. Op die terreine van wetenskap, tegnologie en orga. nisasie het die mens oppermagtig geword. ${ }^{30}$ Die mens het bewus geword van sy geweldige prestasies op verskillende gebiede. Hierdie magstoename by die mens het egter ook 'n keersy, volgens Van Riessen 'n afname van gesag. Daar is 'n duidelike ontwaarding van gesag waarneembaar, volgens Van Riessen. ${ }^{31}$

Die innerlike eerbied vir gesag het die laaste jare snel afgeneem. Die mens wat so magtig geword het en wat die natuur kan beheers, het dit nie meer nodig om nog gesag bo hom te erken nie. $\mathrm{Hy}$ is sigself tot norm. Net datgene het vir hom gesag wat hy as gesag erken en bereid is om te aanvaar. Die moderne magte wat die mens self opgeroep het, gaan egter dwingend gesag oor die mens uitoefen en die mens raak onderworpe aan die magte wat hy self geskep het. Hy kom onder die diktatuur van sy eie magte.

Hieruit moet ons m.i. ook die innerlike verset van die mens teenoor gesag bo hom verklaar. Die moderne mens het mondig geword, ook al noem Van Riessen dit tereg 'n ontspoorde mondigheid, omdat dit 'n mondigheid is van die mens wat met God nie meer rekening hou nie, aangesien hy meen om sonder God te kan klaar kom. ${ }^{32}$

Uit al hierdie faktore kan ons die verset teen wettig gesag verklaar. Die mens wil vry wees, vry van staatsgesag, van universitêre gesag, van ouerlike gesag. Hierdie ontwikkeling moet egter uitloop op anargie of op 'n nuwe diktatuur. Soos die wetteloosheid van die Franse Rewolusie die diktatuur van Napoleon in Frankryk gebring en die normloosheid van die Weimar-republiek in Duitsland die diktatuur van die nasionaal-sosialisme opgeroep het, so staan die mensheid vandag weer op 'n tweesprong: wanneer gesag nie vrywillig aanvaar word nie, sal 'n diktatoriale mag dit kon afdwing. Die mensheid sal altyd bly slinger tussen anargie en diktatuur, wanneer die gesag wat God ingestel het nie aanvaar word nie.

Anargie en diktatuur vind dan ook hulle kulminasiepunt in die koms van die antichris. Hy is die groot anargis, die mens van die anomia, die wetteloosheid ( 2 Thess. $2: 3$ ) en tegelyk die groot wêrelddiktator wat hom verhef bo al wat God genoem word (2 Thess. $2: 4$ ).

\section{Die taak van die Christen ten opsigte van gesag}

Die N.T. roep die gelowiges telkens op tot gehoorsame onderwerping aan die gesag. Dit raak nie alleen die gesag van die ower- 
heid nie (vgl. Rom. $15: 5$ ), maar ook die ouerlike gesag (Ef. $6: 1$ ), ja selfs die gesag wat 'n heer oor sy slaaf uitoefen (Ef. 6 : 5-8; 1 Petr. 2 : 18). Hierin word God gehoorsaam. Gehoorsaamheid aan gesag is 'n kenmerk van 'n ware Christen. Die Christene wat so vreeslik vervolg is in die eerste eeue na Christus was wetsgetroue burgers.

Die vraag wat ons egter ten slotte nog wil bespreek, is of daar ook 'n grens is aan die gehoorsaamheid teenoor gesag? Daar staan tog in die Bybel: „Ons moet aan God meer gehoorsaam wees as aan die mense" (Hand. $5: 29$ ) ? Verset is gelegitimeer wanneer gehoorsaamheid aan aardse gesag ons in konflik bring met Gods gesag. Hierdie verset kan ons dan ook nie rewolusie noem nie.

A. Kuyper het in Amerika in sy bekende Stone-lesings oor die Calvinisme op 'n voortreflike wyse aangetoon hoe die opstand van Nederland teen die Spaanse gesag en die ,glorious Revolution" deur Willem III teen die Stuarts in Engeland en die „declaration of Independence" na die Amerikaanse vryheidsoorlog wesenlik verskil van die Franse rewolusie. ${ }^{33}$ Dit het juis gegaan oor die erkenning van die majesteit van God.

Calvyn het ook in sy Institusie die reg op verset erken. Hy het egter duidelik laat verstaan dat die reg op verset nie aan privati homines toegeken kan word nie, maar alleen aan die volksmagistrate om die willekeur van konings te beteuel. ${ }^{34}$ Die „Plakkaat van Verlatinge" waarmee die Staten-Generaal van die Verenigde Nederlande in 1581 die Spaanse koning Filips II afgesit het, dra duidelik die spore van Calvyn se opvatting oor die reg tot verset. ${ }^{35}$

In hierdie tyd van rewolusie en opstand en verset teen allerlei vorme van wettig gesag is dit dan ook goed om te luister na art. 36 van die Nederlandse Geloofsbelydenis: „Verder is elkeen, van watter hoedanigheid, toestand of staat hy ook al mag wees, verplig om hom aan die owerhede te onderwerp, belasting te betaal, aan hulle eer en eerbied te betoon en hulle gehoorsaam te wees in alles wat nie stry met die Woord van God nie".

Prof. L. Floor.

(Gelewer voor die G.T.V.'s van Johannesburg en Pretoria).

\section{AANTEKENINGE}

1 H. Bavinck: Geref. Dogmatiek, Dl. I4, 1928, p. 433.

2 M. Weber: Wirtschaft und Gesellschaft, 1956, p. 157.

3 H. N. Ridderbos: Het Evangelie naar Matthéüs, DI. II, 1946, p. 261.

4 I. J. du Plessis: Christus as Hoof van Kerk en Kosmos, 1962, p. 126.

5 H. Berkhof: De Katholiciteit der kerk, 1962, p. 57-59. H. N. Ridderbos verklaar pleroma as: het door Hem (nl. Christus) vervulde (gebied of dominium), Paulus ontwerp van zijn theologie, 1966, p. 436.

6 So H. Berkhof: a.w., p. 59.

7 W. Foerster, in: Kittel: Theol. Wörterbuch zum N.T., II, p. 562. 
8 W. Grundmann: Th.W.B. II, p.: „Wir haben hier den Zusammenhang zwischen Geist und Kraft".

9 W. van 't Spijker: Gezag in de kerk, art. in Canon Gestorum Scriptura, 22e jaarg. no. 5/6, 1970, p. 101.

10 W. Grundmann: a. art., p. 309 .

11 H. N. Ridderbos: Paulus, p. 360.

12 B. Holwerda: De Crisis van het Gezag, 1947, p. 9.

13 Vgl. G. Groen van Prinsterer: Ongeloof en Revolutie,4 1913, p. 178, 179.

14 H. J. van Zuthem: Gezag en zeggenschap, 1968, p. 36.

15a Die formulering kom van prof. B. Spoelstra.

15 H. J. van Zuthem: a.w., p. 72.

16 H. J. van Zuthem: a.w., p. 73.

17 H. J. van Zuthem: a.w., p. 72.

18 H. J. van Zuthem: a.w., p. 72.

19 H. J. van Zuthem: a.w., p. 74.

20 H. J. van Zuthem: a.w., p. 74.

21 S. U. Zuidema: De (on)-geloofwaardigheid van onze ekonomische orde, art. in: Mededelingen van de Ver, voor Calv. Wijsbegeerte, December 1969, no. 4, p. 14.

22 G. Groen van Prinsterer: a.w., p. 209: „Te ruime volksvrijheid baart tyrannie".

23 W. H. Velema: De Nieuwe Theologie en de Heilige Schrift, 1970, p. 7.

24 W. H. Velema: a.w., p. 12.

25 W. H. Velema: a.w., p. 12, 16.

26 R. Shaull: Revolutionary Change in Theological Perspective, in die bundel: John C. Bennett: Christian Social Ethics in a Changing World, 1966, passim.

27 Konfrontatie met Van Ruler, in: Rondom het Woord, Theol. Etherleergangen van de N.C.R.V., 11e jaarg., no. 1, Febr. 1969, p. 99.

28 J. Moltmann: Theologie der Hoffnung, 5 1966, p. 299.

29 W. H. Velema: Kritische notities bij „Theologie der Hoffnung", van Jürgen Moltmann, in: Canon Gestorum Scriptura, 19e jaarg., no. 3, Febr. 1967, p. 11-16.

$30 \mathrm{H}$. van Riessen: Mondigheid en de machten, 1967, p. 8.

31 H. van Riessen: a.w., p. 28.

32 H. van Riessen: a.w., p. 101 e.v.

33 A. Kuyper: Het Calvinisme, Zes Stone-lezingen, s.j., p. 75

34 Calvyn: Inst. IV, xx, 31.

35 Vgl. vir die teks: H. Smitskamp en L. C. Suttorp: Historische teksten, 1959 , p. 47 e.v. 